\title{
PENGARUH TERAPI KOGNITIF PERILAKU UNTUK MENGURANGI DEPRESI PADA PECANDU CYBERSEX
}

\section{THE EFFECT OF COGNITIVE BEHAVIOR THERAPY IN REDUCING DEPRESSION LEVEL AMONG CYBERSEX ADDICTS}

\author{
Nurhaerani Haeba \\ Universitas Muhammadiyah Kendari \\ E-mail: rasmuddin@yahoo.co.id
}

\begin{abstract}
This research was aimed to examine the effect of cognitive behavior therapy in reducing depression level among cybersex addicts. The subjects are man and woman in Senior High School Kendari and criterias are based on Cybersex Addict qyestuibbaure and Beck Depression Inventory test. Research design is in experiment one with experimental group and control group. The result of this intervention was analyzed by qualitative approach. Data was collected by questioner of Cybersex Addict, Beck Depression Inventory test, evaluation paper of observation and interview. The conclusion was cognitive behavior therapy be used as one of the form of therapy to decrease the level of depression among cybersex addicts.
\end{abstract}

Key Words: Depression, Cognitive Behavior Therapy, Cybersex

\begin{abstract}
ABSTRAK
Penelitian ini bertujuan untuk mengetahui efek terapi kognitif perilakuan dalam mengurangi tingkat depresi yang dialami pecandu cybersex sehingga berdampak pula terhadap menurunnya tingkat kecanduan pelaku cybersex. Kriteria utama yang dipakai sebagai subjek dalam penelitian ini adalah laki-laki maupun perempuan, tingkat pendidikan minimal SMU yang berdomisili di kota Kendari yang berdasarkan hasil skrining angket kecanduan cybersex dan tes Beck Depression Inventory mengalami kecanduan cybersex yang penyebab utamanya adalah mengalami gangguan depresi. Penelitian dirancang dalam bentuk eksperimen, subjek penelitian dirandom ke dalam kelompok eksperimen dan kelompok kontrol. Hasil intervensi dianalisis dengan pendekatan kualitatif. Metode pengumpulan data dilakukan dengan menggunakan angket kecanduan cybersex dan tes Beck Depression Inventory yang dilaksanakan saat pretes, pascates dan dua minggu setelah pelaksanaan, pemberian tes psikologi, lembar evaluasi observasi dan wawancara. Hasil penelitian menunjukkan bahwa terapi kognitif perilaku dapat menurunkan tingkat depresi pada pecantu cybersex.
\end{abstract}

Kata Kunci: Depresi, Terapi Kognitif Perilaku, Cybersex 
Salah satu media yang dewasa ini banyak dinikmati masyarakat sebagai sumber informasi adalah internet, yaitu media komunikasi yang mampu memberikan pijakan baru dalam jangkauan pergaulan yang meluas. Internet memuat beragam bentuk informasi yang kita butuhkan, mulai dari informasi tentang inovasi terbaru, kajian ilmu pengetahuan dan teknologi, sosial budaya sampai materi pornografi dan hal-hal yang berbau seksualitas.

Salah satu fenomena umum yang muncul adalah perilaku cybersex. Cybersex, menurut Cooper dan GriffinShelley (2002). merupakan aktivitas soliter ataupun aktivitas interaktif yang tujuannya untuk memperoleh gratifikasi seksual. Ada dua bentuk perilaku cybersex terdiri atas dua bentuk, yaitu mengakses situs-situs pornografi (non-interaktif) seperti gambar ataupun video dan terlibat percakapan porno secara online (interaktif).

Cybersex menduduki peringkat pertama sebagai saluran dan situs yang terpopuler dan merupakan sarana terfavorit bagi penggunanya. Cybersex merupakan tempat yang nyaman dengan jumlah komunitas yang sangat besar dan ragam bentuk yang ditawarkan berupa percakapan seputar seks hingga menampilkan gambar-gambar porno di sela-sela percakapan. Kecenderungan melakukan seks secara online berpeluang besar menghasilkan gangguan psikologis baru, yaitu kecanduan cybersex yang memiliki potensi kejahatan seksual. Cybersex merupakan sarana perangsang seksual secara aman tanpa resiko emosional dan fisik dalam bertemu dengan orang lain secara online (Widjaja, 1999).

Berdasarkan survei yang dilakukan oleh Majalah Kosmopolitan (2000) mengenai pendapat responden terhadap cybersex diperoleh hasil bahwa kebanyakan pria $(58 \%)$ dan wanita (64\%) menganggap cybersex sebagai perselingkuhan karena merupakan perzinaan virtual.

Depresi yang dialami individu ternyata memberikan pengarh terhadap perilaku cybersex. Leiblum (1997) menjelaskan bahwa depresi ditemukan sebagai faktor yang berperan sangat besar dalam mengembangkan penggunaan cybersex secara patologis. Pengguna cybersex berlebihan berhubungan dengan adanya hambatan psikologis yang diderita sebagai akibat dari isolasi sosial.

Untuk membantu mengatasi depresi serta membuat prediksi agar lebih akurat tersebut, tampaknya terapi kognitif perilaku dapat dimanfaatkan sebagai salah satu jalan keluar. Terapi kognitif perilaku (coginitive behavior therapy) adalah terapi yang menggabungkan terapi perilaku dan terapi kognitif yang dikembangkan oleh Meichenbaum dan Mahoney (Martin \& Pear, 1996; Sue, Sue, \& Sue, 1986; Prout \& Brown, 1985). Pendekatan kognitif dalam terapi 
perilaku ini sebenarnya merupakan salah satu pengembangan terbaru bidang ini, di mana pendekatan ini memanfaatkan hukum-hukum dalam learning theory untuk membantu mengatasi masalahmasalah psikologis.

Tujuan dari terapi ini adalah untuk mengubah proses berfikir individu agar menjadi lebih rasional dengan menggunakan prinsip dan hukum perilaku pada umumnya. Di samping itu agar individu yang depresif juga mempunyai kemampuan untuk mengenali dan kemudian mengevaluasi atau mengubah cara berfikir, keyakinan dan perasaanya (mengenai diri sendiri dan lingkungan) yang salah sehingga mereka dapat mengubah perilaku yang maladaptive dengan cara mempelajari ketrampilan pengendalian diri dan strategi pemecahan masalah yang efektif (Okun, 1990).

Konsep dasar pemberian terapi kognitif perilaku ini didasarkan pada empat prinsip berikut: pertama, proses kognitif akan menjadi faktor penentu dalam menjelaskan bagaimana manusia berfikir, merasa dan bertindak, kognisi akan memengaruhi emosi dan perilaku manusia. Prinsip kedua adalah adanya keyakinan bahwa manusia mempunyai potensi untuk berfikir rasional dan irasional. Pemikiran yang irasional dapat menimbulkan gangguan emosi dan tingkah laku, maka terapi ini diarahkan untuk memodifikasi fungsi fikir, merasa dan bertindak. Dengan mengubah status pikiran dan perasaannya ini diharapkan tingkah lakunya akan dapat diubah, dari negatif menjadi positif. Prinsip ketiga menekankan bahwa dalam pelayanan terapi, terapi kognitif perilaku ini lebih menekankan kepada masa kini dari pada masa lalu, namun bukan berarti mengabaikan masa lalu. Prinsip keempat, kebanyakan perilaku abnormal atau undesirable dan perilaku normal atau desirable merupakan hasil dari belajar. Jadi, dengan menggunakan prinsip belajar ini pula, maka perilaku yang negatif dan maladaptive akan dikurangi atau diubah menjadi positif dan adaptive (Oemarjoedi, 2004).

Terapi kognitif perilaku ini akan menekankan pada melatih subjek untuk memiliki kemampuan mengatasi (coping) masalah dan mengubah cara berfikirnya agar menjadi lebih adaptive, dilatih untuk mengatur suasana negatif dalam mengurangi depresi, mengenali dan mengatasi berbagai stimulan depresi. Tujuan dari penelitian ini adalah untuk mengetahui efek terapi kognitif perilaku dalam mengurangi depresi pecandu cybersex sehingga berdampak pada turunnya tingkat kecanduan perilaku cybersex.

Pendekatan kognitif perilaku lebih memfokuskan pada proses berfikir dan bagaimana itu mempunyai kontribusi terhadap perilaku dan emosi maladaptive (Prout \& Brown, 1985). Perilaku cybersex adalah salah satu bentuk perilaku dan emosi yang maladaptife. Dengan 
demikian, dapat dirumuskan hipotesis penelitian bahwa perilaku cybersex dapat dikurangi dengan terapi kognitif perilaku.

\section{METODE PENELITIAN}

\section{Subjek Penelitian}

Subjek penelitian ini adalah pecandu cybersex yang penyebab utamanya adalah mengalami depresi. Penetapan subjek didasarkan:

1. Angket kecanduan cybersex dan penyebab utama terjadinya kecanduan adalah mengalami depresi

2. Tes BDI (Beck Depression Inventory) Karakteristik subjek dalam penelitian ini adalah sebagai berikut:

1. Berjenis kelamin laki-laki dan perempuan.

2. Tingkat pendidikan minimal SMU; dimaksudkan agar subjek dapat memahami pertanyaan-pertanyaan dan pernyataan-pernyataan dalam penelitian, selain itu agar subjek mampu melaksanakan aturan-aturan selama pemberian tritmen

3. Minimal 6 bulan sebagai pecandu cybersex.

4. Skor pretes BDI berkisar 16-23 yang menunjukkan depresi sedang; maksud pemberian batas tingkat depresi ini agar setelah diberi tritmen dapat dilihat secara jelas manfaatnya dalam menurunkan tingkat depresi sehingga berdampak pada menurunnya kecanduan cybersex.
Dalam penelitian ini, subjek penelitian berjumlah 6 orang dengan rincian 3 masuk kelompok eksterimen dan 3 lagi masuk kelompok kontrol.

\section{Desain Penelitian}

Penelitian dirancang dalam bentuk eksperimen. Subjek penelitian dimasukkan ke dalam kelompok eksperimen dan kelompok kontrol. Desain yang digunakan adalah pretest-posttest control group design.

Tabel 1. Rancangan Eksperimen PretestPosttest Control Group Design

\begin{tabular}{ccccc}
\hline KE & O1 & $X$ & O2 & O3 \\
KK & O1 & $\sim X$ & O2 & O3 \\
\hline
\end{tabular}

\section{Keterangan:}

KE : Kelompok Eksperimen

KK : Kelompok Kontrol

O1 : Pengukuran sebelum perlakuan (prates)

O2 : Pengukuran setelah perlakuan (pascates)

O3 : Pengukuran dua minggu setelah perlakuan (follow-up)

$X \quad$ : Perlakuan (prosedur menulis pengalaman emosional)

$\sim \mathrm{X}$ : Tidak diberi perlakuan

\section{Pengukuran}

Alat ukur yang digunakan untuk mengetahui keberhasilan terapi kognitif perilaku adalah:

1. Hasil angket pecandu Cybersex dan Beck Depression Inventory saat pretes, pascates dan dua minggu setelah pemberian perilaku 
2. Hasil tugas rumah yang diberikan setiap sesi pertemuan.

\section{Prosedur Penelitian}

1. Perekrutan subjek tahap pertama dengan memberikan angket kecanduan cybersex.

2. Perekrutan tahap kedua subjek yang diberi terapi berdasarkan hasil tes BDI mengalami depresi.

3. Selanjutnya dilakukan random assignment terhadap subjek untuk ditempatkan dalam kelompok yang diberi terapi kognitif perilaku dan kelompok yang tidak diberi terapi perilaku sebagai kelompok kontrol.

4. Agar program intervensi berjalan dengan baik dan dapat mencapai hasil maksimal, pelaksanaan program ini dibantu oleh dua tenaga psikolog sebagai tenaga profesional. Pemberian terapi dilaksanakan secara kelompok (group therapy) selama 6 sesi, satu minggu tiga kali sesi, setiap pertemuan dilaksanakan selama 90 menit. Selama mendapatkan terapi, pada subjek berikan tugas-tugas untuk dikerjakan sebagai pekerjaan rumah dan akan dibahas bersamasama dalam proses terapi. Terapi pada kelompok yang diberi terapi kognitif perilaku dipimpin dan diberikan oleh satu orang psikolog, sedangkan kelompok kontrol dengan tidak diberi perlakuan.
5. Dilakukan pengukuran Beck Depression Inventory dan angket kecanduan cybersex kembali di akhir pemberian terapi selesai dilaksanakan.

6. Melakukan follow up untuk melihat perkembangan perubahan setelah diberi perilaku.

\section{Teknik Analisis Data}

Selanjutnya, evaluasi hasil intervensi yang telah dilakukan dianalisis secara deskriptif - kualitatif.

\section{HASIL PENELITIAN}

Berdasarkan perbandingan dari hasil pengukuran yang dilakukan pada saat prates dan pascates diperoleh data yang menunjukkan adanya penurunan skor tingkat depresi dan terjadi penurunan pada tingakt kecanduan cybersex dari ketiga subjek penelitian dan masih dapat bertahan setelah dua minggu pemberian perilaku. Hal ini dapat dilihat dari perbedaan skor prates lebih tinggi dibandingkan skor pascates dan dua minggu setelah pengukuran. Selanjutnya dalam memberi makna pada masingmasing skor tersebut peneliti mengacu pada tabel tingkat depresi dan tingkat kecanduan cybersex dan keluhan depresi juga batasan skor yang dapat menunjukkan bahwa subjek mengalami depresi atau tidak dan mengalami kecanduan cybersex atau tidak berdasarkan Beck Depression Inventory dan angket kecanduan cybersex, lanjut rinciannya sebagai berikut: 
Tabel 2. Skor Perubahan BDI Subjek Tingkat Kecanduan Cybersex Per Hari

\begin{tabular}{ccccccccc}
\hline \multirow{2}{*}{ Nama } & \multicolumn{2}{c}{ Skor Prates } & \multicolumn{2}{c}{ Skor Postest } & \multicolumn{2}{c}{ Gain Score } & \multicolumn{2}{c}{ Skor Follow Up } \\
\cline { 2 - 9 } & BDI & Cybersex & BDI & Cybersex & BDI & Cybersex & BDI & Cybersex \\
\hline Subjek A & 21 & 5 & 4 & 3 & 17 & 2 & 2 & 0 \\
Subjek R & 17 & 8 & 2 & 3 & 19 & 5 & 0 & 0 \\
Subjek N & 20 & 6 & 1 & 1 & 15 & 5 & 0 & 0 \\
\hline
\end{tabular}

Hasil prates BDI menunjukkan adanya simtom depresi tingkat sedang yang dialami subjek A dengan skor 21 dan frekuensi perilaku cybersex setiap hari 5 kali melakukan, subjek $\mathrm{R}$ dengan skor 17 dan frekuensi perilaku cybersex 8 kali setiap hari, subjek $\mathrm{C}$ dengan skor 20 dan frekuensi perilaku cybersex 6 kali setiap hari. Sebaliknya, untuk pascates subjek A memiliki skor 4, dengan frekuensi perilaku cybersex 3 kali setiap hari, subjek $\mathrm{R}$ memiliki skor 2 dengan frekuensi perilaku cybersex 3 kali setiap hari dan subjek $\mathrm{N}$ memiliki skor 1 dengan frekuensi perilaku cybersex 1 kali setiap hari, artinya masuk dalam kategori tidak ada gejala depresi, namun masih ada keluhan ringan. Demikian pula frekuensi perilaku cybersex mengalami penurunan, namun masih melakukan. Selanjutnya, pada dua minggu setelah pemberian perilaku skor subjek A menunjukkan angka 2 dengan frekuensi perilaku cybersex tidak dilakukan lagi. Subjek B menunjukkan skor 2 dengan frekuensi perilaku cybersex berhenti dan tidak dilakukan lagi, artinya masuk dalam kategori tidak ada gejala depresi, tetapi masih ada keluhan ringan, dan sudah dapat menghilangkan perilaku cybersex. Subjek C menunjukkan skor 0 , artinya dalam kategori tidak ada sama sekali gejala depresi dan sama sekali dapat menghilangkan perilaku cybersex. Hal tersebut menunjukkan bahwa adanya pengaruh pemberian terapi kognitif perilaku dalam menurunkan tingkat depresi pada ketiga subjek.

Berdasarkan tabel di atas, tergambar pula bahwa di antara ketiga subjek, subjek $\mathrm{R}$ memperoleh gain score tingkat depresi lebih tinggi, yaitu 19 poin dengan penurunan frekuensi perilaku cybersex sebesar 5 poin, lalu subjek A dengan 17 poin dengan penurunan frekuensi perilaku cybersex 2 poin dan Subjek R dengan 15 poin dengan penurunan frekuensi perilaku cybersex 5 poin. Artinya, subjek N memperoleh prestasi lebih tinggi dengan kemampuan menurunkan tingkat depresi sampai 19 poin dengan frekuensi perilaku cybersex 5 poin, selanjutnya subjek $N$ dengan kemampuan menurunkan tingkat depresi sampai 17 poin dengan frekuensi perilaku cybersex 2 poin dan subjek $R$ dengan kemampuan menurunkan tingkat depresi sampai 15 poin dengan penurunan frekuensi perilaku cybersex 5 poin. Walau demikian, ketiga subjek 
mampu menurunkan tingkat depresi dari tingkat sedang menjadi tidak ada gejala depresi dan mampu menurunkan frekuensi perilaku cybersex.

Selanjutnya, pada lembar kerja analisis masalah, ketiga subjek mampu meminimalkan beban depresi dari sangat terbebani menjadi sedikit terbebani dengan adanya bukti yang tidak mendukung pikiran negatif, sehingga frekuensi perilaku cybersex dapat dihilangkan. Demikian halnya pada lembar kerja catatan mood harian, ketiga subjek mampu mengidentifikasi mood harian, mengatasi pikiran menyimpang penyebab depresi serta memahami faktor yang memengaruhi mood tersebut, sehingga menciptakan pikiran rasional dan bisa mengurangi beban depresi yang dialami. Semua itu berdampak pada penurunan frekuensi perilaku cybersex. Hal tersebut menunjukkan bahwa dengan pembuatan lembar analisis masalah dan membuat catatan mood harian mampu mengubah pikiran negatif menjadi pikiran positif.

Ketiga subjek juga mampu membuat jadwal aktivitas yang menyenangkan. Subjek A, mampu meningkatkan frekuensi jadwal aktivitas menyenangkan dengan kualitas cukup menyenangkan hingga sangat menyenangkan baik yang dilakukan sendiri maupun bersama suami dan anak-anak. Demikian halnya subjek R, mampu meningkatkan frekuensi aktivitas menyenangkan dengan kualitas cukup menyenangkan hingga sangat menyenangkan yang lebih banyak dilakukan sendiri. Sementara itu pada subjek $N$, frekuensi aktivitas menyenangkan yang dilakukan sedikit dibanding subjek $A$ dan subjek $R$, tetapi memiliki kualitas sangat memuaskan, baik yang dilakukan sendiri maupun bersama orang lain. Hal tersebut menunjukkan bahwa ketiga subjek mampu menciptakan aktivitas menyenangkan.

Melalui lembar identifikasi pikiran positif dan negatif, ketiga subjek mampu mengelola diri secara kognitif untuk mengurangi pikiran negatif dan menggunakan pikiran positif. Pada kasus pertama, subjek A masih didominasi pikiran negatif sehingga masih memberi efek yang mengganggu pada emosi, kognisi dan perilaku sehingga dalam sehari frekuensi perilaku cybersex tinggi yaitu 5 kali sehari. Akan tetapi, pada kasus kedua sudah mampu diminimalkan tetapi masih cukup mengganggu dan pada kasus ketiga, empat dan lima, subjek sudah mampu mengelola diri secara kognitif dan sudah mampu menggunakan pikiran positif sehingga akibat dari situasi yang menekan mampu diminimalkan dan hanya sedikit memengaruhi emosi, kognisi dan tingkahlaku, sehingga dapat secara total menghentikan perilaku cybersex. Demikian halnya subjek $\mathrm{R}$ dan subjek $N$, mampu mengelola diri secara positif sehingga akibat dari situasi yang menyebabkan dapat diminimalkan dari cukup mengganggu menjadi tidak mengganggu emosi, kognisi dan 
tingkah laku, sehingga dapat secara total menghilangkan perilaku cybersex. Hal tersebut menunjukkan bahwa subjek mampu mengidentifikasi pikiran positif dan negatif.

Melalui lembar kerja rencana kerja ketiga subjek mampu membuat daftar situasi yang menyebabkan depresi dan akhirnya menyebabkan frekuensi perilaku cybersex selalu dilakukan setiap hari, menjadi bersikap lebih asertif dalam merespon situasi tersebut. Ketiga subjek mampu menentukan permasalahan yang harus dipecahkan dengan orang lain. Berdasarkan prediksi waktu yang telah ditetapkan, subjek mampu menyelesaikan masalah dengan keterampilan asertif. Hal tersebut menunjukkan bahwa subjek mampu bersikap asertif dan meningkatkan hubungan sosial dengan orang lain.

Berdasarkan uraian di atas, dapat disimpulkan bahwa terapi kognitif perilaku mampu menurunkan tingkat depresi dan dapat menurunkan frekuensi perilaku cybersex, terjadi perubahan pikiran negatif menjadi pikiran positif, mampu menciptakan aktivitas yang menyenangkan, mampu mengidentifikasi pikiran positif dan negatif serta mampu bersikap asertif dan meningkatkan kualitas hubungan sosial.

\section{PEMBAHASAN}

Hasil analisis data pengukuran Beck Depression Inventory (BDI) pada subjek A saat prates dengan skor 21 menunjukkan adanya gangguan depresi tingkat sedang dan berdasar angket perilaku cybersex dengan skor 5 menunjukkan bahwa subjek mengalami perilaku seks menyimpang. Subjek A melakukannya dengan menonton, mendiskusikan dengan temannya dan bahkan melakukan masturbasi dan setiap hari dilakukan 5 kali dan ini dibandingkan dengan hasil tes BDI pascates menjadi 4 menunjukkan hasil tidak adanya gangguan atau menunjukkan tidak adanya gejala depresi menurut acuan pada tabel derajat depresi dan tingkat keluhan depresi dan dapat menurunkan frekuensi perilaku cybersex menjadi 3 poin. Begitu juga setelah dua minggu pasca pemberian perilakuan memperoleh skor 2 menujukkan tidak adanya gejala depresi dan dapat menurunkan tingkat frekuensi perilaku menjadi 0 , artinya sama sekali subjek dapat menghentikan perilaku cybersex. Hal ini berarti pengaruh pemberian perilakuan dapat bertahan.

Pada subjek $\mathrm{R}$ saat prates dengan skor 17 menunjukkan adanya gangguan depresi tingkat sedang dan berdasar angket perilaku cybersex dengan skor 8 menunjukkan bahwa subjek mengalami perilaku seks menyimpang dengan cara online. Subjek R bahkan sering menggoda anak-anak kecil dan masturbasi setiap hari dilakukan 8 kali dan ini dibandingkan dengan hasil BDI saat pascates menjadi 2 menunjukkan hasil tidak adanya gangguan atau menunjukkan tidak adanya gejala depresi menurut acuan pada tabel 
derajat depresi dan tingkat keluhan depresi. Kondisi tersebut berdampak pada turunnya frekuensi tingkat kecanduan seksual menjadi 3 poin. Begitu juga setelah dua minggu pasca pemberian perilakuan, hasil ter BDI memperoleh skor 0 menujukkan tidak adanya gejala depresi dan subjek dapat menghentikan perilaku cybersex secara total. Hal ini berarti pengaruh pemberian perilakuan dapat bertahan.

Demikian halnya pada subjek $N$, hasil BDI prates dengan skor 20 menunjukkan adanya gangguan depresi tingkat sedang dan berdasar angket perilaku cybersex dengan skor 6 menunjukkan bahwa subjek mengalami perilaku seks menyimpang dengan cara online. Subjek $\mathrm{N}$ melakukannya dengan menonton, mendiskusikan dengan temannya dan bahkan melakukan masturbasi setiap hari 6 kali dan ini dibandingkan dengan hasil tes BDI pascates menjadi 1 menunjukkan hasil tidak adanya gangguan atau menunjukkan tidak adanya gejala depresi menurut acuan pada tabel derajat depresi dan tingkat keluhan depresi dan perilaku cybersex dapat diturunkan menjadi 1 . Begitu juga setelah dua minggu pasca pemberian perlakuan memperoleh skor 0 menujukkan tidak adanya gejala depresi dan subjek dapat menghentikan perilaku cybersex secara total. Hal ini berarti pengaruh pemberian perilakuan dapat bertahan.
Leiblum (1997) menjelaskan bahwa depresi ditemukan sebagai faktor yang berperan sangat besar dalam mengembangkan penggunaan cybersex secara patologis. Pengguna cybersex berlebihan berhubungan dengan adanya hambatan psikologis yang diderita sebagai akibat dari isolasi sosial.

Hasil analisis data di atas membuktikan bahwa terapi kognitif perilaku efektif untuk diberikan pada penderita depresi tingkat ringan dan sedang. Diskusi dan tugas-tugas rumah yang diberikan melatih subjek untuk memiliki kemampuan mengatasi masalah dan mengubah cara berfikirnya menjadi lebih adaptive. Pendekatan kognitif perilaku lebih memfokuskan pada proses berfikir dan bagaimana itu mempunyai kontribusi terhadap perilaku dan emosi maladaptive (Prout \& Brown, 1985).

Subjek selalu menilai setiap kejadian sebagai sesuatu yang negatif dan menyebabkan tekanan. Tekanan yang dialami dianggap subjek sebagai kegagalan dirinya dan akan merusak masa depan. Kegiatan online dan chatting merupakan tempat pelarian untuk mengurangi hal-hal negatif dalam diri mereka. Pendapat negatif subjek tersebut sesuai dengan apa yang diutarakan oleh Beck (1985) bahwa suatu pengalaman yang sama akan memengaruhi dua orang dengan cara yang berlainan. Perbedaan ini sangat dipengaruhi oleh cara pandang 
individu yang bersangkutan terhadap sebuah peristiwa. Cara pandang atau interpretasi dari kognisi yang sering keliru adalah melibatkan distorsi negatif terhadap pengalaman hidup, penilaian diri yang negatif, pesimisme, dan keputusasaan. Pandangan negatif yang dipelajari ini selanjutnya menyebabkan perasaan depresi (Kaplan dkk., 1997). Depresi didahului oleh kekacauan atau gangguan pada pikirannya yang kemudian mendasari gangguan pada perasaannya (Sue dkk, 1986). Mereka lebih mengharapkan kegagalan dari pada keberhasilan, cenderung menonjolkan dan membesarkan kegagalan dan mengecilkan arti keberhasilan, suka menyalahkan diri sendiri pada suatu situasi yang kurang beres (Atkinson dkk, 1999).

Oleh karena itu, tujuan dari terapi kognitif perilaku adalah untuk mengubah proses berfikir individu agar menjadi lebih rasional dengan menggunakan prinsip dan hukum perilaku pada umumnya. Di samping itu agar individu yang depresif juga mempunyai kemampuan untuk mengenali dan kemudian mengevaluasi atau mengubah cara berfikir, keyakinan dan perasaanya (mengenai diri sendiri dan lingkungan) yang salah sehingga mereka dapat mengubah perilaku yang maladaptive dengan cara mempelajari ketrampilan pengendalian diri dan strategi pemecahan masalah yang efektif (Okun, 1990).

\section{SIMPULAN DAN SARAN}

\section{Simpulan}

Terapi kognitif perilaku dapat menurunkan tingkat depresi pada pecandu cybersex sehingga berdampak pada turunnya tingkat kecanduan perilaku cybersex

\section{Saran}

1. Lembaga-lembaga kesehatan dan sosial, program terapi ini dapat dimanfaatkan sebagai salah satu model intervensi bagi penanganan depresi

2. Peneliti selanjutnya untuk melakukan terapi kognitif perilaku kepada jumlah yang lebih besar sehingga dapat dibandingkan dan mengetahui variasi perubahan pada masingmasing subjek

3. Peran psikolog diharapkan dapat memberi pelayanan yang lebih singkat dan mudah sehingga bisa diberikan pada setiap penderita depresi.

\section{UCAPAN TERIMA KASIH}

Ucapan terima kasih kepada:

1. Direktorat Jenderal Pendidikan Tinggi, Kementrian Pendidikan Dan Kebudayaan sebagai pihak pemberi dana

2. Rektor Universitas Muhammadiyah Kendari.

3. Lembaga Penelitian Universitas Muhammadiyah Kendari. 


\section{DAFTAR PUSTAKA}

Atkinson, R.L. \& Atkinson, R.C. (1999). Pengantar Psikologi. Jilid 2. Edisi 8. Alih Bahasa: Nurjanah, T. \& Dharma, A. Jakarta: Erlangga

Anthony, M. H. Cruess, D. G., Cruess, S. Lutgendorf, S., Kumar, M., Ironson, G., Klimas, N., Flethcher, M. A., \& Schneiderman, N. (2000). Cognitive-Behavioral Stress Management Intevension Effect on Anxiety, 24-Hr Urinary Norepinephrine Output, and T-Cytotoxic/Suppressor Celss Over Time Among Symptomatic HIC-Infected Gay Men. Journal of Consulting and Clinical Psychology, 68 (1), 31-45.

Beck, AT. (1985). Depression: Causes and Treatment. Philadelphia: University of Pennsylvania.

Cooper, A., \& Griffin-Shelley, E. (2002). Introduction The Internet: The next Sexual Revolution. In A. Cooper (Ed.), Sex and the Internet: A GuideBook for Clinicians. New York, NY: Brunner-Routledge.

Kaplan \& Sadock. (1997). Sinopsis Psikiatri IImu Pengetahuan Perilaku Psikiatri Klinis. Alih Bahasa : Widjaja Kusuma. Jakarta : Binapura Aksara.
Leiblum, S.R. (1997). Sex and the Net: Clinical Implication. Journal of Sex Education and Therapy, 22, 21-28.

Martin, G., \& Pear, J. (1996). Behavior Modification: What It Is and How to Do It. New Jersey: Prentice Hall, Inc.

Sue, D., Sue, D.W., \& Sue, S. (1986). Understanding abnormal behavior (2nd Ed.). Boston: Houghton Mifflin.

Oemarjoedi, A. K. (2004). Pendekatan Cognitive Behavior dalam Psikoterapi. Jakarta : Penerbit Creativ Media.

Okun B. F. (1990). Seeking Connection in Psychotherapy. San Francisco \& Oxford: Jossey-Bass Publishers

Pruot. H. T., \& Brown, D. T. (1985). Counseling and Psychotherapy with Children and Adolescents: Theory and Practice For School ang Clinical Settings. Brandon, Vermont: Clinical Psychology Publishing Co, Inc.

Widjaja, A. (1999). Kekuatan Sex dalam Penyembuhan. Jakarta. PT. Interaksara. 